\title{
CONCEPÇÕES DE PROFESSORES DE ENFERMAGEM SOBRE DROGAS
}

\author{
Conceptions for teachers of nursing on drugs \\ Concepciones para los profesores de enfermería en materia de \\ drogas
}

Gertrudes Teixeira Lopes ${ }^{1}$

Halyne Limeira Pessanha ${ }^{2}$

\section{RESUMO}

Objeto: concepções dos docentes da Faculdade de Enfermagem da Universidade do Estado do Rio de Janeiro FENF/UERJ sobre o fenômeno das drogas. Objetivos: identificar as concepções dos docentes da FENF/UERJ sobre o fenômeno das drogas e discutir estas concepções. Pesquisa de campo com abordagem qualitativa. 0 cenário foi a FENF/UERJ. Os sujeitos foram dez docentes. A base para inclusão dos sujeitos foi o levantamento das áreas de ensino que abordavam o fenômeno das drogas, realizado na faculdade. Utilizamos a entrevista temática e a pesquisa documental. 0 roteiro de entrevista compôs-se de 14 questões. Observaram-se os aspectos éticos da Resolução 196/96. A análise e tratamento dos dados deram-se pelo método de Análise de Conteúdo de Bardin. Percebemos que os professores concebem as drogas por diferentes vertentes e dentro de diversos modelos de atenção ao usuário de drogas. A concepção marcante foi a droga como doença, sendo fortemente influenciada pelas condições sociais e individuais.

Palavras-chave: Enfermagem. Drogas ilícitas. Ensino. Formação de conceito.

\begin{abstract}
Object: conceptions of teachers from the University School of Nursing of the State of Rio de Janeiro FENF / UERJ in the provision of content on the phenomenon of drugs. Objectives: to identify the conceptions of the professors of the FENF/UERJ on the phenomenon of the drugs and to argue these conceptions. A field research with a qualitative boarding. The scenario was the FENF/UERJ. The citizens had been ten professors. The base for inclusion of the citizens was the survey of the education areas that approached the phenomenon of the drugs carried through in the college. We have used the thematic interview and the documentary research. The interview script possessed 14 questions. One observed the ethical aspects of Resolution 196/ 96. The analysis and treatment of the data were given for the method of Analysis of Content of Bardin. We have perceived that the professors inside conceived the drugs for different sources and of diverse models of using attention users of drugs. The main conception was drug as illness, being strongly influenced by the social and individual conditions.
\end{abstract}

Keywords: Nursing. Street Drugs. Teaching. Concept Formation.

\section{Resumen}

Objeto: concepciones de los profesores de la Escuela Universitaria de Enfermería del Estado de Rio de Janeiro FENF / UERJ en el suministro de contenidos sobre el fenómeno de las drogas. Objetivos: identificar los conceptos de los maestros de la FENF / UERJ sobre el fenómeno de las drogas y discutir estos conceptos. Campo de búsqueda con un enfoque cualitativo. El escenario fue la FENF / UERJ. Los sujetos fueron diez profesores. La base para la inclusión del tema fue el levantamiento de las áreas de la enseñanza que abordan el fenómeno de las drogas, celebrada en la universidad. Utilizamos la entrevista y el tema de la investigación documental. La hoja de ruta de la entrevista tiene 14 puntos. Hubo los aspectos éticos de la Resolución 196/96. El análisis y el procesamiento de datos ha sido el método de análisis de contenido de Bardin. Notado que los docentes el diseño de fármacos para diferentes secciones y dentro de los diferentes modelos de atención al usuario de drogas. El diseño es llamativo las drogas como una enfermedad, y muy influido por las condiciones sociales e individuales.

Palabras clave: Enfermería. Drogas llícitas. Enseñanza. Formación de Concepto. 


\section{INTRODUCC̃̃O}

Este estudo tem como objeto as concepções dos docentes da Faculdade de Enfermagem da Universidade do Estado do Rio de Janeiro FENF/UERJ sobre o fenômeno das drogas.

A questão do uso e abuso de substâncias psicoativas, especialmente as ilícitas, tem ocupado lugar de destaque nas discussões da sociedade em geral, como a mídia, campanhas eleitorais, planos governamentais, meio acadêmico, além de fazer parte das principais preocupações dos pais, nas últimas décadas.

A forma como se aborda habitualmente o tema traz a impressão de que se trata de algo novo, de um mal contemporâneo quando, na realidade, o uso de substâncias psicoativas é um fenômeno que acompanha toda a história da humanidade. ${ }^{1} 0$ mesmo pode ser dito sobre a busca do prazer e a necessidade da satisfação.

A droga não pode ser caracterizada somente como um composto químico, mas como um produto essencialmente determinado por um rótulo ideológico, aliado às condições de acesso e consumo. ${ }^{2}$

0 consumo de substâncias psicoativas constitui fenômeno relativamente freqüente, sobretudo entre jovens. Um grande contingente de pessoas experimenta tais substâncias. Destes, uma parcela considerável passa a fazer uso, na maioria das vezes, de forma ocasional, geralmente sem conseqüências danosas. Uma pequena parte destes usuários ocasionais passa para padrões de uso de risco, e alguns deles vêm a se tornar dependentes.

No Brasil, o primeiro levantamento domiciliar sobre o uso de drogas psicotrópicas foi realizado em 2001 através do Centro Brasileiro de Informações sobre Drogas Psicotrópicas (CEBRID) da Universidade Federal de São Paulo (UNIFESP), que obteve dados de quase $50 \%$ da população das 107 maiores cidades do Brasil. Neste levantamento foi constatado que o consumo no Brasil de drogas lícitas - especialmente o álcool e o tabaco - é superior ao das drogas ilícitas; $19,4 \%$ dos entrevistados já haviam feito uso de tabaco e álcool em algum momento da vida, constituindo-se em uma população de 9.109.000 pessoas em números absolutos. A estes dados são acrescidos os índices de uso das drogas ilícitas, como a maconha $(6,9 \%)$, seguida dos solventes $(5,8 \%)$ e das medicações controladas por receitas médicas $(4,3 \%){ }^{3}$

0 mesmo estudo acrescenta que existe uma tendência mundial que aponta para o uso cada vez mais precoce de substâncias psicoativas, incluindo o álcool, sendo que tal uso também ocorre de forma cada vez mais pesada. No Brasil, estudo realizado pelo CEBRID revelou percentual altíssimo de adolescentes que já haviam feito uso de álcool na vida: $74,1 \%$. Quanto ao uso freqüente, e para a mesma amostra, chegamos a $14,7 \%$. Ficou constatado que $19,5 \%$ dos estudantes faltaram à escola após beber e que $11,5 \%$ brigaram sob o efeito do álcool. ${ }^{3}$
Os dados estatísticos encontrados na população brasileira para uso de drogas em algum momento da vida são menores quando comparados com os dados do Chile $(20,2 \%)$ e dos Estados Unidos (38,9\%), porém este fato não faz menor 0 problema relacionado ao fenômeno das drogas em nosso país. ${ }^{3}$

0 problema tem se espalhado nas sociedades industrializadas, atingindo dimensões epidêmicas, transformando-se num sintoma inquietante de um novo e profundo mal-estar na civilização e trazendo sérias conseqüências não só no que diz respeito à saúde, como também aos grandes gastos financeiros para os governos. ${ }^{4}$

Nesta perspectiva, identificar as concepções dos docentes sobre o fenômeno das drogas se faz importante uma vez que estas concepções influenciam sobremaneira o papel do enfermeiro diante deste fenômeno. As formas como os professores concebem o problema é transmitida para os acadêmicos de enfermagem, o que passa a fazer parte da formação profissional dos futuros enfermeiros. Segundo o Novo Dicionário Aurélio da Língua Portuguesa ${ }^{5}$, concepção pode ser definida como: 0 ato de conceber ou criar mentalmente, de formar idéias, especialmente abstrações.

0 papel do enfermeiro no fenômeno das drogas pode ser entendido como essencial, uma vez que este profissional pode desenvolver atividades para prevenir o uso de drogas, atuar sobre os fatores de risco para o uso/abuso de drogas e promover a integração da família e dos demais seguimentos sociais. Pode atuar também na saúde fortalecendo os fatores protetores, com vistas à melhoria da auto-estima e desenvolvendo estratégias para a manutenção da saúde, entre outros. ${ }^{6}$

Para desenvolver este estudo, formulamos como objetivos: identificar as concepções dos docentes da FENF/UERJ sobre o fenômeno das drogas e discutir estas concepç̃es no mundo contemporâneo.

Discutir o fenômeno das drogas nos meios acadêmicos se configura um assunto de grande importância, uma vez que 0 variado número de vertentes que o assunto suscita, aliado ao contexto econômico-social no qual vivemos, faz com que se crie o compromisso ético de constantemente revisar conceitos sobre a temática e criar comportamentos e atitudes que mudem o cenário atual.

Espera-se com este estudo que ocorra a reflexão por parte dos docentes de instituições de nível superior, em especial da Enfermagem, sobre a importância do ensino do fenômeno das drogas, considerando sua natureza social. Pois entendemos que no Enfermeiro é construído o potencial humano chave para alcançar a mudança e a transformação nos indivíduos, família e comunidade. Assim a concepção que o docente tem a respeito deste tema é o que vai balizar o ensino do fenômeno das drogas na graduação e assegurar a continuidade lógica, racional e psicológica que a assistência necessita. 


\section{TRAJ ETÓRIA METODOLÓGICA}

Por ser este um estudo que busca discutir as concepções dos docentes em relação às drogas nas diferentes áreas do ensino na Faculdade de Enfermagem da Universidade do Estado do Rio de Janeiro, optamos por utilizar a abordagem qualitativa para o seu desenvolvimento, na forma de uma pesquisa de campo. A pesquisa tem como cenário a Faculdade de Enfermagem da Universidade do Estado do Rio de Janeiro - FENF/UERJ. Os sujeitos deste estudo foram os docentes da FENF/UERJ que abordam o fenômeno das drogas em algum momento do ensino na graduação.

Utilizamos como base para os critérios de inclusão dos sujeitos os resultados de um estudo ${ }^{6}$ desenvolvido na FENF/ UERJ pelas professoras do Programa de Mestrado, no qual foi realizado um levantamento das áreas de ensino que abordavam o fenômeno das drogas, além do desejo de participar do estudo. Foram entrevistados 10 (dez) professores que lecionam na FENF/UERJ e claramente expressaram discutir a temática droga em algum momento da formação do futuro enfermeiro. Os docentes entrevistados foram identificados pela letra "E" precedida por um número arábico.

Faz-se importante esclarecer que mesmo constando no estudo "El Currículo de Enfermeria con el Contenido de Drogas para los Programas de Pregrado y Postgrado: la experiência de la CICAD en América Latina" que existe carga horária específica para a discussão da temática droga em vários momentos do currículo de graduação da FENF/UERJ, a maioria dos professores relatou não abordar estes conteúdos durante as atividades didático-pedagógicas da graduação em Enfermagem. Este fato dificultou a coleta de dados, retardando este procedimento metodológico.

Para desenvolver este estudo, utilizamos as técnicas de entrevista temática no molde semi-estruturado. 0 roteiro de entrevista continha 8 questões relativas à identificação dos sujeitos e 6 questões relativas ao objeto de estudo. As entrevistas foram gravadas e logo após transformadas em texto, mediante a assinatura do Termo de Consentimento Livre e Esclarecido por cada um dos entrevistados. Por tratar-se de pesquisa que envolve seres humanos, foram observados os aspectos éticos disciplinados pela Resolução 196/96 do Conselho Nacional de Saúde. 0 estudo foi aprovado pelo Comitê de Ética do Hospital Universitário Pedro Ernesto, protocolo número 1678 - CEP/HUPE, no dia 7 de março de 2007.

0 processo de análise e tratamento dos dados se deu pelo método de Análise de Conteúdo à luz de Bardin ${ }^{8}$. As Unidades de Registro - UR deram origem aos temas e, em seqüência, às categorias analíticas: Formação Profissional dos Docentes da FENF/UERJ Relativa ao Fenômeno das Drogas e As Concepções dos Professores da FENF/UERJ sobre o Fenômeno das Drogas

\section{APRESENTAÇÃO E DISCUSSÃO DOS RESULTADOS}

\section{Formação Profissional dos docentes da FENF/ UERJ relativa ao Fenômeno das Drogas}

0 enfermeiro tem um papel primordial na promoção, prevenção, redução de danos e reinserção social dos indivíduos que fazem uso de alguma droga - lícita ou ilícita, pois convive com este grupo em seu ambiente de trabalho. ${ }^{9}$ Desta forma se faz premente o preparo do enfermeiro para atender esta população, assegurando uma melhoria na qualidade de vida aos seus clientes.

Planejar a formação profissional na área de drogas é uma tarefa delicada, especialmente em um país de proporções continentais, como o Brasil. ${ }^{10}$ De um lado temos a crescente produção de conhecimentos, de outras posições ideológicas e tabus arraigados. Para melhor assistirmos os usuários de drogas, devemos nos cobrar o exercício de constante revisão de conceitos diante de novas evidências.

Para desenvolver as habilidades necessárias ao cuidado no fenômeno das drogas durante a formação dos futuros enfermeiros, os docentes necessitam discutir esta temática em todos os âmbitos da academia. Em relação ao seu conhecimento, os docentes enfatizam que estes são oriundos de diferentes processos cognitivos e experiências obtidas ao longo de sua carreira profissional, conforme explicitam os depoimentos que se seguem.

Eu me interessei por esse fenômeno muito antes de entrar para esta faculdade. Quando eu fui convidada para participar de um movimento antidrogas a partir de um grupo que trabalhava na Venezuela com educação para saúde. (E7)

Mas a gente não tem uma formação especifica pra lidar com isso, como lidar com essa questão da droga mais diretamente; a gente não tem uma formação especifica, é o que a experiência de vida nos ensinou. Quer dizer, a gente vai lidando com isso de acordo com o aprendizado de vida. (E5)

Estes depoimentos ratificam que o conhecimento sobre 0 fenômeno das drogas foi adquirido ao longo da carreira profissional, portanto revelam que a formação acadêmica não ofereceu conhecimento e nem habilidade suficientes para enfrentar situações como o fenômeno das drogas, cuja abrangência ultrapassa fronteiras, abarca dimensões internacionais e nacionais, políticas, econômicas, sociais, éticas culturais e outras, não respeitando crenças, credos, famílias e sociedades. Portanto, é compreensível que os professores de uma maneira geral apresentem dificuldades em abordar 0 assunto com os alunos, uma vez que não detêm conteúdos suficientes para levar uma discussão mais aprofundada em sala de aula. 
Eu não tenho formação profissional no fenômeno das drogas. Nenhuma, e também não foi exigido pela faculdade. (E1)

Eu não tenho nenhuma experiência prática com o conteúdo de drogas. (E4)

Agora a gente não tem uma formação específica em relação a isso, isso aí a gente percebe claramente quando uma pessoa está sob o efeito do cigarro, da maconha, do álcool. (E5)

Esta dificuldade de abordar a temática droga expressa nas falas dos depoentes reforça que a carência na discussão deste fenômeno dentro da graduação em Enfermagem é um problema de longa data, inviabilizando o diálogo sobre 0 assunto e 0 encaminhamento de soluções para as pessoas que fazem uso/ abuso das substâncias.

Estudos que discutem a formação do Enfermeiro relativa ao fenômeno das drogas apontam que os acadêmicos de enfermagem apresentam dificuldades na abordagem com 0 cliente usuário de drogas, gerando conceitos sobre o fenômeno que não correspondem às exigências e necessidades desta população. ${ }^{11,12}$

As dificuldades relatadas pelos docentes perpassam 0 campo teórico, quando os mesmos apontam a dificuldade de falar com o cliente usuário de drogas por ocasião das mais diversas experiências práticas da vida profissional, seja na atividade docente, seja na assistência direta ao cliente em vários âmbitos do cuidar.

Agora existem outras drogas, a gente percebe um comportamento estranho na pessoa, mas não saberia classificar qual a droga que provavelmente foi ou está sendo utilizada. [...] Agora quando a gente percebe o envolvimento dessas outras drogas que não são aceitas, como abordar isso com a mulher? (E5)

[...] porque na realidade a gente tem dificuldade até de identificar até o que o outro está dizendo. Quantas vezes o outro diz que está usando, ele está demonstrando que está usando, e a gente está fingindo que não está vendo. (E6)

A questão dessa temática, eu vou ser muito sincera pra você, eu não conheço muito. [...] E aínós temos alunos que fumam, que bebem. Eu já tive uma aluna [...] alguns alunos, uns 2 ou 3 alunos de uma outra instituição, em outro estado que eram usuários de droga e eram assim muito difíceis de se lidar. [...] realmente assim fica meio velado, todo mundo sabe, mas ninguém fala. (E8)
Podemos inferir que a carência de conhecimentos relativos ao fenômeno das drogas relatadas pelos docentes pode influenciar na identificação do problema e no cuidado ao cliente usuário de drogas, como explicitado nas falas anteriores.

Esta dificuldade na abordagem foi também evidenciada junto aos enfermeiros que atuam no Programa Saúde da Família, no qual foi observado que as dificuldades identificadas situam-se no campo técnico-científico, da subjetividade e das relações, gerando certo distanciamento do profissional enfermeiro destas questões. 0 estudo vai além e aponta certa estagnação do processo de formação dos futuros enfermeiros perante este fenômeno. ${ }^{1}$

Diante deste quadro surgiu a oportunidade de a Faculdade de Enfermagem da UERJ se engajar em uma proposta que tinha como objetivo qualificar docentes universitários para serem mediadores na discussão do fenômeno das drogas junto às instituições formadoras, visando instrumentalizar os estudantes para enfrentar as demandas que a sociedade determinava.

A discussão do tema drogas já fazia parte dos estudos de alguns docentes da FENF/UERJ, principalmente na área de Psiquiatria e Saúde Pública a partir de experiências no desenvolvimento de pesquisas científicas na área. Com isso houve um avanço significativo na concepção dos professores e alunos a partir da aproximação em níveis nacional e internacional da Faculdade com a Comissão Interamericana para o Controle do Abuso de Drogas - CICAD.

Esta aproximação se deu através do convênio com a Organização dos Estados Americanos - OEA/CICAD e teve como desdobramento a realização de seminários, mesas redondas e oficinas com o objetivo de reunir o corpo docente e discente da FENF para se aproximarem das discussões e reflexões sobre o fenômeno das drogas.

[...] veio um convite para participar de um seminário em Washington. Então nós fomos pra Washington, foi o primeiro passo da nossa faculdade adentrando nesse projeto. (E7)

O primeiro passo era sensibilizar a faculdade, $e$ então a gente recebeu recurso para fazer três seminários [...] levantamos as perspectivas dos professores e alunos para saber como íamos trabalhar. (E7)

Dentre as iniciativas decorrentes do convênio firmado entre as duas instituições, alguns professores foram indicados para ampliar seus conhecimentos sobre o fenômeno das drogas, o que se evidenciou tanto no Brasil quanto no exterior com cursos de especialização e pós-doutoramento. Atualmente a FENF conta com três professores especialistas nesta área, dois professores com pós-doutorado e dois professores em fase de pós-doutoramento. 
Sou especialista em saúde mental e psiquiatria e sou especialista na área de fenômeno de drogas cuja especialização concluí pela USP, pela Escola de Ribeirão Preto em parceria que a gente firmou com a CICAD. (E2)

Até eu entrar neste programa de pós-doutoramento eu tinha uma concepção relacionada às drogas como um fenômeno extremamente complexo que envolvia a questão da saúde. [...] Depois que eu participei desse processo de pós-doutoramento com o aprofundamento das leituras e discussões, eu vejo hoje que o fenômeno das drogas é um fenômeno [...] é uma pandemia, é um fenômeno mundial (E10)

0 acúmulo de leituras e discussões sobre o fenômeno das drogas fez com que os docentes atualmente tenham uma visão mais ampliada sobre este problema. Esta mudança no eixo de suas percepções tende para a discussão do fenômeno das drogas como um problema mundial, com macro e micro determinantes que afetam sobremaneira os países da América Latina.

A droga deve ser vista dentro de um modelo multidimensional e crítico, e dentro deste contexto devem-se contemplar as dimensões nacionais e internacionais relativas às drogas. 0 investimento da Faculdade de Enfermagem na atualização do corpo docente, seja mediante a realização de seminários, oficinas, palestras, debates, seja através de um processo formal de qualificação, propiciou uma mudança cognitiva destes profissionais, ensejando mudanças significativas na concepção do fenômeno das drogas pelo corpo docente.

Por sua vez, a incorporação dos aspectos cognitivos na prática profissional perpassa pelo campo do conhecimento e da subjetividade, refletindo crenças, experiências, valores, ideologias e sentimentos sobre o fenômeno vivenciado. ${ }^{1}$

\section{As Concepções dos Professores da FENF/UERJ sobre o Fenômeno das Drogas.}

No que diz respeito às concepções dos docentes em relação ao fenômeno das drogas, torna-se mister a identificação de tais concepções, o que melhor possibilita a análise e a compreensão da sua forma de atuar diante do problema e como as discussões com os alunos são desenvolvidas.

Ao analisarmos as entrevistas, evidenciamos um grande número de falas relativas às concepções dos docentes sobre 0 fenômeno das drogas. Nestas falas os docentes concebem 0 problema como um fenômeno multifacetado e multicausal, que perpassam os contextos social, econômico, familiar e educacional. Os docentes também concebem a droga como doença que gera dependência e demanda discussões de caráter ético-jurídico.

Ainda dentro destas falas prevaleceram as concepções de caráter preventista, com a identificação das drogas como um problema de saúde pública que necessita de um olhar centrado no sujeito, e não na droga em si.
A reflexão a respeito da droga como um assunto multifacetado, de natureza ampla e complexidade e contextualidade própria, certamente também demanda uma análise de natureza macro, envolvendo discussões sobre as mudanças do cenário mundial, cada dia mais dinâmicas, gerando incertezas que influenciam e reconfiguram os papéis e as relações entre as nações. A droga então emerge como um problema tanto social quanto de saúde, exacerbado em conseqüência do processo de globalização. ${ }^{13}$

Esta discussão pode ser evidenciada nas falas abaixo:

Seria uma gama de fatores relacionados que envolvem o adolescente principalmente. Enquanto algumas pessoas só recorrem na fase adulta mesmo, nós teremos problemas emocionais e familiares, então na realidade eu acho que não fica só na parte social. Seria uma gama de fatores relacionados no nosso dia-a-dia, com a nossa vida mesmo, muito conturbada, muito violenta na qualidade nossa. (E1)

[...] e são várias coisas envolvidas com relação à droga. Depois que eu participei desse processo de pós-doutoramento com o aprofundamento das leituras e discussões, eu vejo hoje que o fenômeno das drogas é um fenômeno mundial que envolve, além dessas questões complexas da dependência química como doença, as relações sócio-culturais, etc. Isso envolve as questões politicas e de geografia do poder político no planeta. (E10)

As concepções que os docentes expressam em relação ao fenômeno das drogas demonstram o viés da multicausalidade, mas também evidenciam que a droga ainda é tratada como doença, que necessita de tratamento específico. Nos depoimentos que se seguem podemos identificar a relação das drogas com outras patologias, gerando 0 adoecimento físico, psíquico e social dos indivíduos.

A droga também é uma doença e que até hoje em dia vem desenvolvendo outras doenças. (E6)

[...] você sabe que principalmente o alcoolismo é uma doença, mas têm outras drogas aí que fazem o indivíduo adoecer não só psiquicamente, física, social. (E2)

Nas falas dos docentes existe uma idéia de droga e seu uso/abuso como doença ou conseqüência desta. A clara associação destes conceitos geralmente é transmitida aos alunos de graduação, fazendo com que os mesmos concebam também a droga como um problema que deve ser medicalizado e institucionalizado.

Podemos observar o alcoolismo sendo apontado como uma doença pelos acadêmicos de enfermagem do último período de graduação, quando se inferiu que essa atitude dos discentes 
em relação ao dependente pode estar relacionada ao enfoque recebido durante o aprendizado e até ao conhecimento adquirido por outras vias de informação que não o acadêmico. ${ }^{11}$

A complexidade do fenômeno das drogas é ainda evidenciada na fala do depoente $\mathrm{E} 10$, que enseja uma discussão sobre o tratamento do usuário de drogas, desvinculando o cuidado à concepção de doença.

Então é muito, muito mais complexo do que eu lidar com uma pessoa que é dependente química $e$ tratá-la como simplesmente uma questão de doença, e não é por aí. (E10)

Esta visão segue os novos modelos de atenção aos usuários de drogas no âmbito nacional e mundial, em que o problema drogas passa a ser visto não só como uma questão de dependência física de uma substância, mas sim dentro de um amplo contexto no qual o usuário esta inserido.

Nesta lógica, estudos enfatizam que, no enfrentamento das situações vinculadas ao uso de álcool e outras drogas, 0 enfermeiro pode utilizar estratégias de aproximação com 0 usuário, mesmo em situação de tratamento e reabilitação, e neste aspecto o enfermeiro pode incentivar a participação do cliente em grupos de apoio para orientação, acolhimento e outras estratégias terapêuticas, com vistas às mudanças de comportamento do usuário e ao desenvolvimento de um estilo de vida mais saudável. ${ }^{11,12}$

Mesmo com esta mudança de paradigma relativo ao acompanhamento dos usuários de drogas, observamos falas que percebem a droga como geradora de dependência física.

Droga na minha concepção é tudo que é utilizado por uma pessoa e que gera algum tipo ou alguma forma de dependência. (E5)

0 uso de drogas é definido pela Organização Mundial de Saúde (OMS) como um conjunto de manifestações fisiológicas, comportamentais e cognitivas no qual o consumo de drogas atinge a máxima prioridade para o indivíduo. ${ }^{2}$ Nesta perspectiva, o indivíduo perde o controle sobre sua vontade, que se concentra totalmente no consumo da substância.

Este entendimento sobre o fenômeno gera estigmas e preconceitos em relação aos usuários e ao problema do uso da droga em si. E a droga passa a ser vista dentro de um modelo que criminaliza e exclui o usuário do convívio social e familiar, como podemos perceber na fala que se segue.

Associado a isso tem as concepções habituais do cidadão comum, é um problema de polícia, é um problema de violência, é um problema. (E10)

Esta afirmação pode ser corroborada pelos achados em um estudo que visa identificar os conhecimentos e opiniões dos trabalhadores relacionados ao alcoolismo ${ }^{4}$, pois os entrevistados em vários momentos apontam as relações entre as representações negativas geradas na sociedade ao indivíduo que faz uso abusivo de álcool ou outras drogas. A visão de que o usuário de substâncias é alguém fraco o torna socialmente rejeitado.

Entre as diversas abordagens sobre o fenômeno das drogas nas sociedades modernas, destaca-se aquela que enfatiza 0 combate das drogas, apresentando-a como a única maneira capaz de enfrentar e erradicar este problema. Esta argumentação caracteriza-se por um discurso mais sensacionalista do que científico e mais moralista do que isento de valores e juízos valorativos, gerando certa beligerância que encobre uma série de fatores que, de certo, contribuem decisivamente para a expansão do fenômeno. ${ }^{14}$ Esta visão pode gerar certo desconfor to e inabilidade do enfermeiro ao lidar com os indivíduos que utilizam drogas.

As concepções dos docentes extrapolam a discussão sobre o fenômeno das drogas das questões de saúde em si e concebem este problema como permeado por uma infinidade de fatores, dentre os quais o fator econômico tem grande peso para o uso/ consumo de drogas em todo o mundo.

Então, a minha concepção sobre as drogas, para mim ela é só um elemento que por um lado serve aos interesses econômicos, que dá dinheiro. (E3)

Existe uma relação estreita entre as drogas e o que pode ser identificado como 'motivação econômica' para o uso de drogas, em que a necessidade do consumo leva os usuários a cometerem delitos para assegurar a obtenção da substância. ${ }^{15}$

Porém a economia da droga não se restringe somente aos roubos e delitos. Desde a metade do século XX as drogas se transformaram num dos maiores negócios, numa indústria poderosa e num comércio ramificado. 0 nível econômico em termos de insumos propiciados talvez seja ultrapassado apenas pela economia de energias e telecomunicações. Existem grandes interesses nos circuitos de produção, circulação, distribuição e consumo de drogas. ${ }^{13}$

Em todas as concepções evidenciadas nas falas dos docentes e discutidas até o momento, a concepção de drogas como um problema social é percebida. Este fato é mais explicitado na fala seguinte, na qual o problema das drogas é correlacionado diretamente com fatores sociais de consumo, principalmente.

Tenho uma convicção de que a droga tem um peso na saúde das pessoas, gera problemas sociais, mas ao mesmo tempo eu entendo que sempre na humanidade teve o uso de determinadas substâncias e em alguns momentos históricos tem uma aceitação maior e em algumas culturas tem uma aceitação maior. (E9) 
Os profissionais de saúde devem deixar de lado o conceito de que o uso de drogas é um problema do usuário, abordando0 através de medidas repressivas, para tratá-lo como uma questão que afeta a todos: usuário, família e sociedade, ou seja, uma visão holística considerando os múltiplos desdobramentos do fenômeno. ${ }^{13}$

Este fenômeno que abarca um grande conjunto de concepções deve também estar centrado na prevenção do uso e do consumo de drogas em qualquer fase da vida dos seres humanos. Esta preocupação é evidenciada na fala a seguir:

Em relação à concepção do fenômeno drogas, como venho estudando isso já há algum tempo, a minha concepção vem muito da minha pesquisa, das pesquisas que a gente vem realizando, das leituras. [...] Hoje minha concepção é muito no aspecto preventivo. (E2)

A concepção que focaliza a prevenção faz parte da Política do Ministério da Saúde para a atenção integral a usuários de álcool e outras drogas, que entende que reconhecer o consumidor, suas características e necessidades, assim como as vias de administração de drogas, exige a busca de novas estratégias de contato e de vínculo com ele e seus familiares, para que se possam desenhar e implantar múltiplos programas de prevenção, educação, tratamento e promoção adaptada às diferentes necessidades. Para que uma política de saúde seja coerente, eficaz e efetiva, deve ter em conta que as distintas estratégias são complementares, e não concorrentes, e que, portanto, o retardo do consumo de drogas, a redução dos danos associada ao consumo e a superação do consumo são elementos fundamentais para sua construção. ${ }^{16}$

Nessa perspectiva, o enfermeiro pode desempenhar importante papel na promoção da saúde diante de vários aspectos, dentre eles a formação e capacitação dos profissionais de saúde visando à redução da demanda de álcool e drogas na América Latina. Entendendo que com mudanças de paradigmas, atuando na formação dos enfermeiros, poderão ocorrer novas configurações no cuidado dos diversos grupos da sociedade nos níveis de promoção, prevenção e integração social.

O que eu vejo é que, na realidade, a questão drogas é uma questão que está na educação, então a escola tem um papel primordial nesse aspecto de discutir até pela vulnerabilidade. (E2)

Cabe à universidade oferecer, no decorrer da graduação, as condições para que 0 aluno adquira as competências necessárias ao exercício da profissão. Portanto, é durante a formação de enfermagem que deve ser fornecido o preparo para o futuro enfermeiro atuar na redução da demanda de drogas e para cuidar dos seres humanos que estão envolvidos neste contexto. ${ }^{13}$

Esta capacitação formal dos profissionais de saúde, em especial dos enfermeiros, vem também atender a uma demanda de saúde dentro da realidade brasileira, pois hoje o problema do uso de drogas se configura como um grande problema de saúde publica. Sendo assim, requer um modelo de atenção incluindo a promoção da saúde, o enfoque na prevenção do uso/abuso visando produzir as transformações sociais que propiciem uma melhor qualidade de vida da sociedade como um todo. ${ }^{13}$

Pensando na droga de uma maneira mais ampla, as não-lícitas e as lícitas, o cigarro, o álcool, eu vejo assim: embora a gente trabalhe com essa questão de saúde, e a minha formação é muito voltada para a saúde pública, a gente entende que o cigarro é uma droga, é um problema de saúde pública, que o álcool é uma droga e é um problema de saúde pública. (E8)

A fala acima corrobora as discussões oriundas do Ministério da Saúde, que constatou que o uso de drogas tomou proporção de grave problema de saúde pública no País, encontrando ressonância nos diversos segmentos da sociedade, pela relação comprovada entre o consumo e agravos sociais que dele decorrem ou que o reforçam. 0 enfrentamento desta problemática constitui uma demanda mundial. De acordo com a Organização Mundial de Saúde, cerca de $10 \%$ das populações dos centros urbanos de todo o mundo consomem abusivamente substâncias psicoativas, independentemente de idade, sexo, nível de instrução e poder aquisitivo. ${ }^{16}$

As ações as quais a política do Ministério da Saúde se refere devem estar centradas no sujeito, na sua motivação para o uso, conseqüências do abuso e prevenção primária e secundária para o uso/abuso de drogas. Esta preocupação surge na fala do docente a seguir.

Então, eu acho que essa questão me levou a essa reflexão, de que hoje você tem que estar voltado para o sujeito, para o espaço onde ele vive, para as crenças, os valores e a cultura desse sujeito. (E2)

Dentro desta análise, se faz necessário ter claro que o cliente usuário de drogas é o sujeito do seu tratamento e que o enfermeiro deve ser inserido na relação com este, como um mediador, como um elemento de ajuda. Esta compreensão é determinante no processo de recuperação do indivíduo. ${ }^{11}$ 


\section{CONCLUSÕES}

Após a análise das concepções dos docentes da Faculdade de Enfermagem da UERJ, percebemos que estas se apresentam por diferentes vertentes e dentro de diversos modelos de atenção ao usuário de drogas. Estas concepções nos fazem entender de que forma a problemática é vista e desenvolvida dentro do currículo de graduação da FENF/UERJ, o que possibilita identificar que o enfoque dado na formação do futuro enfermeiro passa pela concepção de drogas como doença, mas evidencia o enfoque centrado no sujeito, buscando estratégias de prevenção do uso/abuso de drogas em todos os âmbitos do cuidado de enfermagem.

\section{Referências}

1. Moutinho ECVS. 0 enfermeiro na prevenção do uso/abuso de drogas: uma perspectiva para o Programa Saúde da Família [dissertação de mestrado]. Rio de Janeiro (RJ): Faculdade de Enfermagem/UERJ; 2005.

2. Organização Mundial de Saúde-OMS. Classificação de transtornos mentais e de comportamento da CID 10. Descrições clínicas e diretrizes diagnósticas. Porto Alegre (RS): Artes Médicas; 1993.

3. Carlini ELA, Galduroz JCF, Noto AR, Nappo SA. Levantamento domiciliar sobre uso de drogas psicotrópicas no Brasil: estudo envolvendo as 107 maiores cidades do país - 2001. São Paulo (SP): CEBRID/ UNIFESP; 2002.

4. Fonseca FF. Conhecimentos e opiniões dos trabalhadores sobre o uso e abuso de álcool. Esc Anna Nery Rev Enferm 2007 dez; 11 (4): $599-604$.

5. Wright MGM. La contribución de la enfermería frente al fenomeno de las drogas y la violencia en América Latina: un proceso de construcción. Cienc Enferm 2002 dez; 8(2): 1-11.

6. Ferreira ABH. Novo Dicionário Aurélio da Língua Portuguesa. $3^{\mathrm{a} e d .}$ Curitiba (PR): Positivo; 2004.

7. Organización de los Estados Americanos - OEA. Comisión Interamericana para el Control del Abuso de Drogas - CICAD. El currículo de enfermeria con el contenido de drogas para los programas de pregrado y postgrado: la experiência de la CICAD en América Latina. Washington (USA): Rio de Janeiro(RJ): UERJ/FENF; 2005.

8. Bardin L. Análise de conteúdo. Lisboa(P0): Ed 70; 1977.
Identificamos que as concepções dos docentes da Faculdade de Enfermagem da UERJ relativas ao fenômeno das drogas se encontram dentro de conceitos macro e micro determinantes que partem da percepção de que o uso/abuso de drogas é uma doença, o que é for temente influenciado pelas condições sociais e individuais presentes na nossa sociedade. Estas concepções passam pelo distanciamento das pessoas, pela falta de laços afetivos e pelo desmazelamento da estrutura familiar, sendo estes considerados fatores importantes para a aproximação das pessoas com a droga. Outra concepção importante foi a questão econômica influenciando fortemente o consumo de drogas, uma vez que a economia da droga gera grandes cifras dentro do mercado mundial.

9. Lopes GT, Luis MAV. A formação do enfermeiro e o fenômeno das drogas no Estado do Rio de Janeiro- Brasil: atitudes e crenças. Rev Latino-am Enfermagem 2005 out; 13 (n.esp): 872-79.

10. Silveira DX, Moreira FG. Panorama atual de drogas e dependências. São Paulo (SP): Atheneu; 2006.

11. Lopes GT. A formação do enfermeiro e o fenômeno das drogas no Estado do Rio de Janeiro- Brasil: conhecimento, atitudes e crenças [tese de pós-doutorado] Ribeirão Preto(SP): Escola de Enfermagem /USP; 2004.

12. Pillon SC. 0 uso do álcool e a educação formal dos enfermeiros [tese de doutorado]. São Paulo (SP): Escola Paulista de Medicina/ UNIFESP; 2003.

13. Carraro TE, Rassool GH, Luis MAV. A formação do enfermeiro e o fenômeno das drogas no sul do Brasil: atitudes e crenças dos estudantes de enfermagem sobre cuidado. Rev Latino-am Enfermagem 2005 out; 13

(n. esp): 863-71.

14. Bucher R, Oliveira SRM. 0 discurso do "combate às drogas" e suas ideologias. Rev Saude Publica 1994 abr; 28 (2): 137-45.

15. Gonçalves AM. Cuidados diante do abuso e da dependência de drogas: desafio da prática do Programa Saúde da Família [tese de doutorado]. São Paulo (SP): Escola de Enfermagem /USP; 2002.

16.Ministerio da Saude(BR). Secretaria de Atenção à Saúde. A política do Ministério da Saúde para atenção integral a usuários de álcool e outras drogas. 2a ed. Brasília (DF); 2004 